\title{
535
}

RING CHROMOSOME 12 SYNDROME Angel R. Colon and Rebecca Jesse Georgetown Univ. School of Med., Washington (Spon. by Joseph A. Bellanti) Advances in the development of banding techniques have facilitated the identification of a number of new chromosomal abnormalities. We studied a 13 mo. old girl with a history of failure to thrive, developmental delay and dysmorphic features. Chromosomal analysis revealed ringed chromosome 12. J.T. was the product of an uncomplicated second pregnancy of a $24 \mathrm{yr}$. old woman. Birth weight and height were close to the 3 rd percentile. At 13 mos. her weight age was 1 mo., height age was 3 mos. and head circumference was at 3 rd percentile for 3 mos. She had epicanthal folds, mildly cupped low set ears, high arched palate, short neck with low set hairline. Total hand length was that of a $1.5 \mathrm{mo}$. old and clinodactyly and single crease of left 5th finger. Developmentally she functioned betrypsin banding showed a ring number was 46 in all cells an of cells showed varioge percent breaks in chromatids. The purpose eate the clinical findings and natural history of ring chromosome 12 syndrome. There are only two known cases of this syndrome with which we compared our findings. It appears that the amount of genetic material deleted from chromosome 12 determines the degree of physical abnormalities and developmental delay. The relatively high rate of the loss of the ring 12 points out the fragility of the ring chromosome.

536 CHONDRIAL CARBAMY PHOSPHATE SYNTHETASE DEFICIENCY. Mahoney, and Leon E. Ro. Rosenberg. Barbara Crowley, Maurice J. Pediatrics, Yale Univ. Sch. Med. and Dept. Pediatrics, Rhode Island Hosp., New Haven, CT and Providence, RI

Inherited deficiency of hepatic mitochondrial carbamyl phosphate synthetase (CPS I), the first enzyme of the urea cycle, is a rare cause of hyperammonemia and protein intolerance. The paucity of affected individuals and the lack of family studies have hitherto precluded definition of the mode of inheritance. We now report in its entirety a family with two children affected with partial CPS I deficiency. The proband, a 16 year old girl, was ascertained when hyperammonemia accompanied an episode of encephalopathy. Moderate psychomotor retardation in the proband and her two sibs ( 1 female; 1 male) necessitated diagnostic liver bippsies for urea cycle enzyme assays. Isolated deficiency of CPS I was observed in the proband's liver ( $6 \%$ of control mean) and that of her sister ( $5 \%$ of control); the brother's activity was well within the range of appropriate control values (see table). CPS I activity Significantly, CPS I activity Subject $\quad(\mu \mathrm{mol} / \mathrm{hr} / \mathrm{mg}) \quad$ in the liver of both unrelated roband 0.18 parents fell between the defiFemale Sib $0.16 \quad$ cient values in the affected Male Sib 2.35 girls and the normal range. Father $\quad 0.95$ lother $\quad 1.57$ that CPS I deficiency is inher $2.98+0.58(x+1 S D)$ ted as an autosomal recessive

\section{HYPOPHOSPHATASIA (A FAMILY STUDY) AND TURNER SYNDROME} Sharon L. Maby, H. Lawrence Vallet, Carl Wirth and ments of Pediatrics and Orthopedics, Medical College, DepartNew York State Department of Health, ATbany, New York.

A patient with Turner Syndrome (TS) $\left(45, X_{0}\right)$ diagnosed by age 2 years had at age 5 years, rachitic changes on chest $x$-ray, a healing traumatic fracture of the left femur and metaphyseal changes consistent with hypophosphatasia (H). The diagnos is was confirmed by a low serum alkaline phosphatase (AP) $(125 \mathrm{mu} / \mathrm{ml})$ in the presence of a fracture, elevated urinary excretion of phosphoethanolamine (PEA) $(33.6 \mathrm{mg} /$ day) and early shedding of deciduous teeth. Malabsorption, glomerular and tubular renal diseases were excluded by appropriate investigations. Because of limited growth potential in TS and further impairment by the concommitent occurence of $\mathrm{H}$, a trial of phosphate therapy was felt to be indicated. A bone biopsy after tetracycline labelling was performed prior to the initiation of therapy; biopsy will be repeated after 6 months of therapy $(1 / 78)$. The clinical response to therapy suggests a nearly twofold increase in growth rate.

Historically and radiologically the paternal side was free disease; $4 / 7$ in the mother's sibship showed radiographic evidence of bone dysplasia in childhood. Total AP was low in the mother and her affected sister, and normal in the father. PEA

excretion studies and AP isoenzyme determinations are in progress and $H$. The family study suggests that the $H$ is transmitted as an autosomal dominant trait.

538 THYLMALONIC-ADIPIC ACIDURIA: A NEW DEFECT OF BUTYRATE PXIDATION ASSOCIATED WITH HYPOGLYCEMIA. S. Mantagos, M. Genel and K. Tanaka (Spon. by L.E. Rosenberg).

Depts. Hum. Gen. and Peds., Yale Univ. Sch. Med., New Haven, CT. A 5 year old girl with recurrent hypoglycemia, acidosis and normal development was found to excrete in her urine massive quan tities of ethylmalonic acid (ENA), adipic acid (AA) and hexonylglycine $(H G): 670-780,210-740$ and $190-390 \mu \mathrm{g} / \mathrm{mg}$ creatinine, respectively, vs. normal values of $<9 \mu \mathrm{g} / \mathrm{mg}$ for each. Since butyry COA can be carboxylated to form EMA, and hexanoyl COA can be

either w-oxidized to $A A$ or conjugated with glycine to form $H G$, this pattern of urinary metabolites suggested a deficiency of putyryl COA dehydrogenase, a mitochondrial enzyme oxidizing both putyryl and hexanoyl COA. Such a deficiency was supported by a medium chain triglyceride challenge which markedly augmented EMA excretion, and by studies on oxidation of $\left[1-1^{4} \mathrm{C}\right]$ butyrate by cultured skin fibroblasts which revealed $14 \mathrm{CO}_{2}$ production by pa-

tient's cells consistently $<15 \%$ of that in 6 control lines.

The urinary findings in our patient resemble those seen in Jamaican vomiting sickness and glutaric aciduria type II, both haracterized by defects of multiple acyl COA dehydrogenases. The fultured cell findings noted above, however, the excretion of onl. ninimal amounts of glutarate and the results of oral lysine and eucine loading tests make these diagnoses most unlikely. We sug gest that our patient suffers from an inheritent isolated deficiency of butyryl COA dehydrogenase. The hypoglycemia may be explained by accumulation of EMA, which has been shown to inhibit pitochondrial malate transport, a rate limiting step in gluconeo-

\section{9}

PRESUMPTIVE EVIDENCE FOR THE PRESENCE OF 2 ACTIVE $X$ CHROMOSOMES IN A BALANCED X-AUTOSOL L- TRANSLOCATION. Laure1 S. Marshall, Mildred L. Kistenmacher, Hope $H$. Punnett, St. Christopher's Hospital for Children and Department of Pediatrics, Temple University School of Medicine, Philadelphia, Pa.

In human somatic cells, $X$ chromosomes in excess of one are late replicating. In balanced $X$-autosome translocation, the general rule is that the normal $x$ is late replicating. We are reporting the first such translocation in which there is no late replicating $X$ in $1 / 3$ of cells analyzed. A 6-year-old girl with the Beckwith-Wiedemann syndrome has a balanced, de novo, $\mathrm{X} ; 1$ translocation (G-banded karyotype is $46, \mathrm{X}, \mathrm{t}(\mathrm{X} ; 1)$ (Xpter $\rightarrow$
$\mathrm{Xq} 26:: 1 \mathrm{q} 12 \rightarrow$ lqter; lpter $\rightarrow 1 \mathrm{q} 12: \mathrm{Xq} 26 \rightarrow \mathrm{Xq}$ ) terminal pulse method followed by acridine orange or Hoechst 33258 stain and giemsa in 2 successive lymphocyte cultures, the normal $X$ was identified as late replicating in approximately $66 \%$ of metaphases. In the remaining $34 \%$ of cells, neither the normal $X$ nor the $X t$ appeared to be late replicating. In these cells, regions of chromosomes 4 and 13 , known to be late replicating, are clearly identifiable. In no case did the sma11 Xq portion in the reciprocal translocation chromosome appear as late replicating. This finding serves as presumptive evidence for the presence of 2 active $X$ chromosomes in a balanced X-autosome translocation.

Supported in part by NIH grants \# RR75 and CA 19834

540

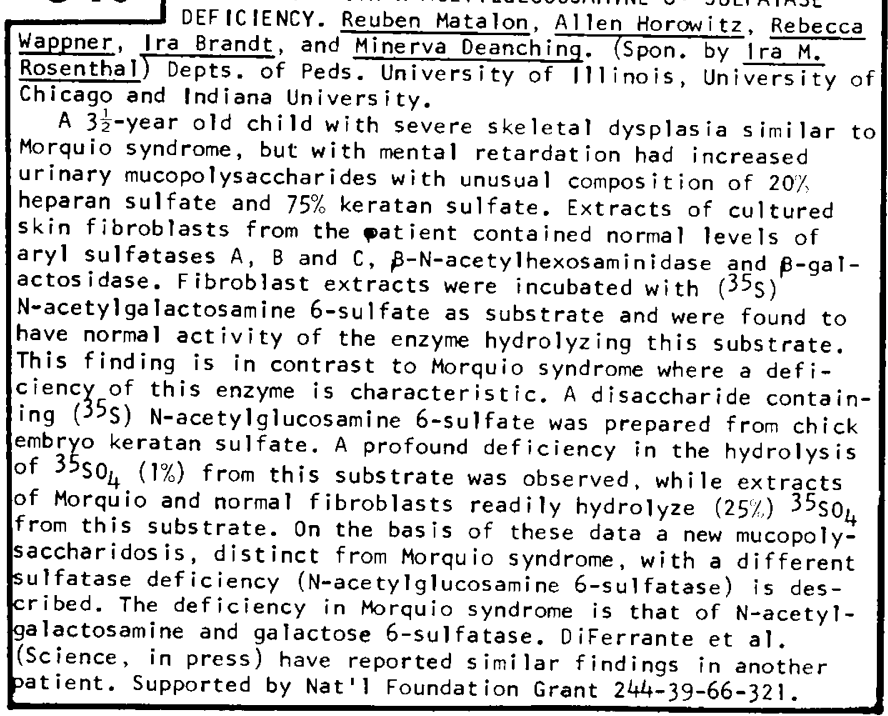

